\title{
Originalien
}

\section{Experimental Studies on the Relation between the Cerebrospinal and the Labyrinthine Fluid.}

\author{
By
}

Tatsuo Kibata, M. D.

(From the Department of Oto-Rhino-Laryngology, The Government Medical Scbool, Okayama, Japan; Director, Pruf. F. Tanaka).

\section{Table of Contents.}

I. Introduction.

II. Historical Review.

III. Experiments.

Experiment No. I.

Experimental Studies with Macroscopical Examination.

1. Materials and Methods.

2. Results.

3. Discussion of the Results.

Experiment No. II.

Experimental Studies with Micro-chemical Tests.

1. Materials and Methods.

2. Results.

3. Discussion of the Results.

Experiment No. III.

Experimental Studies with Histological Examinations.

A. Experiment with Indian Ink.

1. Materials and Methods.

2. Results.

3. Discussion of the Results.

B. Experiment with Ferrocyanide Solution.

1. Materials and Methods.

2. Results.

3. Discussion of the Results.

C Injection of Coloring Substance into the Subarachnoid Space, plus Opening of A Part of Labrinthine Cavity.

1. Materials and Methods.

2. Results a. Experiment with Indian Ink.

b. Experiment with Ferrocyanide Solution.

IV. Summary.

3. Discussion of the Results.

V. Conclusions.

VI. Bibliography.

VII. Explanation of Colored Plates. 


\section{Introduction.}

Notwithstanding a remarkable advancement in the studies of physiology an pathology of the labyrinth, and in spite of the labyrinth's frequent contractions $t$ various diseases, it shows no progress, up to the present, in way of treatment of th diseases of the internal ear. "This is because the anatomical and physiologica peculialities of the labyrinth, not only make the surgical treatment of it most difficull but also make it difficult of access for ordinary medical administration.

According to Babinski, ${ }^{1)}$ Barany, ${ }^{2)}$ Hennebert, ${ }^{\text {, }}$ Weill ${ }^{32)}$ and his fellow workers etc., they have often experienced a significant result by a lumber puncture on the patient with labyrinthine vertigo. It is also reported, ${ }^{16,28)}$ that syphilis of the interna ear has improved much by Swift-Ellis' treatment when the other treatments hav failed. The experiments in the past have shown that various substances administerec intravenously have failed to reach the labyrinth, ${ }^{11,2 i)}$ and that the intravital staining of the labyrinth by intravenous injections has been proved to give negative findings. ${ }^{\text {, 20] }}$

From these facts, it came to my mind that, in the treatment of the diseases of the internal ear, a striking result which otherwise is impossible may be obtained by administering medicaments through the subarachnoid space, if it is only possible that the medicament so administered would reach the internal ear through the medium of the cerebrospinal fluid. To bring this consideration into effect, it is necessary to make preliminary studies on the relation between the cerebrospinal and the labrinthine fluid. In fact, the studies, I believe, are not only interesting from a scientific viewpoint, but also important from a standpoint of practical medicine. The present studies have been made with the above consideration.

\section{Historical Review.}

General text-books of anatomy and of otology take for granted, that the cerebrospinal fluid communicates with the labyrinthine fluid.. However, if we carefully study the original literature to which most of these text-books refer, we cannot but feel doubtful. It is worth note, therefore, that the question has been aroused recently among many medical authorities and the studies have been carried out by them, and yet no definite view has been expressed, which receives general acceptance.

In 1860, Hyrtl") supposed the perilymph of the labyrinth to be the cerebrospinal fluid, as he found on a monkey that linseed oil injected upward into the cranial subarachnoid space through the severed end of the spinal cord at the cervical 
region reached the perilymphatic spaces of the labyrinth through the aquaeductus cochleae. In 1881, he advocated again in his text-book, "(0) "Twenty-four years ago, I demonstrated that the substance injected into the subarachnoid space reached the vestibule, the cochlea and the semicircular canals through the internal auditory meatus, and therefore, supposed the perilymph to be the cerebrospinal fluid. I have proved later the correctness of this supposition. In these descriptions, there will be seen a contradiction regarding the pathways to the labyrinth of the injected substance.

In 1869 , Schwalbe ${ }^{2+1)}$ gave a brief description of his experiment on a rabbit and a dog killed by bleeding from the femoral artery, in which the dura mater cerebri was exposed and an injection of a Berlin blue solution into the subarachnoid space was made. The injected solution reached the perilymphatic spaces of the labyrinth through the internal auditory meatus.

Key and Retzius ${ }^{13,18)}$ in 1870-75, injected into the subarachnoid space of a dog or of a rabbit with a Berlin blue solution or an emulsion of cinnabar, and found that the injected substance filled the sheaths of the acustic nerve and the perilymphatic spaces of the labyrinth, but very rarely reached through the lamina cribrosa to the nerve branches in the lamina spiralis, and therefore, no direct communication between the lymphatic spaces of the labyrinth and the nerve sheaths existed. However, in man, they found that the coloring substance injected into the subarachnoid space never reached the perilymphatic spaces of the labyrinth; it reached the aquaeductus cochleae, but not to the scala tympani. The coloring substance injected from the round window did not reach the aquaeductus cochleae.

In 1877 , Weber-Liel ${ }^{11}$ reported that endolymphatic spaces were connected with the intracranial sack (saccus endolymphaticus) through the aquaeductus vestibuli, and the perilymphatic spaces were connected with the subarachnoid space through the aquaeductus cochleae. Two years later, he published a detailed report ${ }^{30)}$ on another experiment of his on a human skull in which he made the suction and injection tests with Bearle's blue solution, and claimed that he proved the facts previously reported by him. Many after would seem to have accepted his findings, as most of the text-books cite them.

Hasse, ${ }^{7)}$ 1877, was of the opinion that the perilymph was connected mostly with the subarachnoid space through the ductus perilymphaticus, but partly with the subdural space through the dural sheaths of the nerve, and the endolymph was connected on one hand with the saccus endolymphaticus where it communicated with the lymph of the epidural and the intradural lymph spaces by diffusion, and 
on the other hand with the arachnoid sheaths of the blood vessels and of the acusti nerve. He gave no concrete proofs, however, simply described his experiment on : frog in which an emulsion of colored lime was injected into the ductus perilymphaticus

Ruedinger, ${ }^{19,20)}$ in 1888 , claimed that the saccus endolymphaticus had inter. epithelial crevices as well as many minute foramina through which the endolympl communicated with the meningeal lymphatics. However, Siebenmann ${ }^{232}$ in 1919 made a careful histological examination of the organ and denied Ruedinger's findings

Siebenmann ${ }^{22}$ made similar experiments as Weber-Liel. According to his description in 1899 , the perilymphatic spaces of the labrinth did not communicate with the subdural space, but communicated in the main with the subarachnoid space through the aquaeductus cochleae. He also said that the perineural and the perivas. cular lymph spaces, especially the latter, next to the aquaeductus cochleae, the most important passage way between the scalas of the cochlea and the intracranial spaces.

Boehm and Davidoff, ${ }^{3)}$ in 1903, described that the perilymph reached the perineural sheaths of the nerve that innervated the macula acusticae and the crista ampullares, and they said perineural sheaths related to the subdural and the subara? chnoid space.

Boenninghaus ${ }^{4}$ in 1908 stated that the endolymphatic and the perilymphatic spaces of the labyrinth communicated with the subarachnoid space, and the endolymphatic spaces possibly through the perineural lymph spaces of the three branches of the eighth nerve, and the perilymphatic spaces through the aquaeductus cochleae,

In 1918, Fleischmann ${ }^{6)}$ obtained negative findings in the intra vitam staining of the internal ear and therefore, denied a self-production in the labyrinth of the labyrinthine fluid, but came to hold the opinion that the labyrinthine fluid originates in the cerebrospinal fluid.

In 1919, Wittmaack ${ }^{33)}$ published a voluminous paper in which he said that an Indian ink injected into the subarachnoid space of a living cat reached the entire course of the aquaeductus cochleae, but did not reach farther up to the scala tympani:

Alexander Rejtoe $e^{17)}$ in 1921, expressed his opinion that there is no direct communication between the perilymph of the labyrinth and the cerebrospinal fluid, but they communicate only indirectly through the blood and the lymph vessels. However, he did not give any proofs of his own.

Chilow $^{5)}$ in 1923, injected into the cisterna magna of a dead cat with a methylene blue solution under pressure of $130-150 \mathrm{~mm}$. Hg. After a short time, on puncturing the second tympanic membrane, he obtained methylene blue solution. 
He also made other studies on the elation of the pressures in the labyrinth to those in the subarachnoid space and to the atmospheric pressures in the external acoustic meatus. From the results of these experiments, he came to the conclusion that the cerebrospinal fluid has some relation to the labyrinthine fluid.

In $1923, S z a s z^{25)}$ measured the degrees of refraction both on the cerebrospinal fluid and on the perilymph of a dog, and found that the two fluids were not the same, the former being thicker than the latter. He expressed his opinion however, that he would admit a possible communication between the two fluids through the aquaeductus cochleae, and that if such a communication is possible, the perilymph should flow towards the cerebrospinal fluid.

In order to prove the existing view on the aquaeductus cochleae through which the cerebrospinal fluid communicates with the labyrinthine fluid, Karlefors ${ }^{12)}$ in 1924, made experiments in imitation of the suction and injection tests employed by Weber-Liel and by Siebenmann on the petrous bones removed from three human corpses. He made opening in the superior semicircular canal to which a suction pump was applied and a Berlin blue solution was dropped in the lower exit of the aquaeductus cochleae. The Berlin blue solution was seen at the opening of the superior semicircular canal. The results of the experiments on the reverse way was the same. He confessed, however, that no positive opinion could be established by such experiments as these.

In summarizing the above literature, it will be seen that almost all of the previous investigators (Hyrtl, Schwalbe, Key and Retzius, Weber-Liel, Hasse, Siebenmann, Chilow, and Karlefors etc.) tried to demonstrate a communication between the cerebrospinal and the labyrinthine fluid' only by means of their experiments on dead materials in which colored substances were injected either into the subarachnoid space or into the lymphatic cavities of the labyrinth. However, such experiments as have been carried out on dead materials would hardly seem to present us any evidence of the real existence of a communication between the two fluids during life time.

Ruedinger's view on the existence of a communication between the endolymphatic spaces and the intracranial cavities is worth no noting, as his view was barely upon the histological findings of the saccus endolymphaticus, that have recently been denied by a careful study of Siebenmann.

Boehm and Davidoff, Boenninghaus, and Rejtoe gave no evidence of their own experiments and therefore, they, too, are without value. Fleischmann's view 
on the possible identity of the cerebrospinal and the labyrinthine fluid should also be left out of account, as he gave no evidence except the negative findings in his experiment of the intra vitam staining of the labyrinth. The experiments of Wittmaack, Chilow and Szasz respectively cast, without doubt, some light upon the relationship between the two fluids, but still it is regretted that they furnish little aid in the solution of this problem.

Yet aside from the adverse criticism as has been pointed out in the above, a survey of the literature reveals widely devergent view among those predecessors and nothing has yet been decided regarding the passage ways through which the cerebrospinal and the labyrinthine fluid communicate, and we still hold only theories of a possible communication between the cerebrospinal and the labyrinthine fluid through one or more of the aquaeductus cochleae, the saccus endolymphaticus, and the perivascular and the perineural lymph spaces.

A careful review of the experiments by our predecessors, in short, reveals that their experiments were carried out with improper materials and inadequate methods, and therefore, unsatisfactory or incorrect findings, from which any conclusions they, have reached, would hardly seem to give us confidence. Accordingly, it may not be an exaggeration to say that ever since the first advocacy of Hyrtl, the relation between the cerebrospinal and the labyrinthine fluid has not yet been fully studied and the problem is still left entirely in abeyance today. Thus, in the present state of our ignorance, I feel keenly the need of more thorough studies on the problem under question.

\section{Experiments.}

As has been pointed out in the above, what we feel is disatisfactory with the findings of our predecessors lies in the fact that the experiments their findings based upon have been carried out with inadequate or imperfect methods. And the most defective point in their experiments exists in the employment of dead materials. From the above view-point, Wittmaack's experiment, being carried out on a living animal, is said to be the only one worthy to note. It is regretted, however, that his experiment has as yet some defect as will be discussed in the later paragraph.

Taking a warning by the above facts, I laid much stress upon carrying out experiments on living animals with methods that would keep the animals as natural as possible. For this purpose, the method of injecting into the subarachnoid space by a simple puncture of the cisterna magna of a rabbit reported by Yamaokat? in 
1915 gave me a suggestion. The method has since Yamaoka's report, been fairly widely employed by fellow men in this country. The technic is as simple and easy as that of a hypodermic injection, and does practically no damage whatever to the animals. Furthermore, as it can be used on many animals at a time and the experiment is easily carried out, a correct judgement of the results will be expected.

In view of these facts, utilizing the cisternal puncture of Yamaoka's method, I carried out all the experiments in the present paper mostly with rabbits. Only healthy rabbits with normal hearing organs, of approximately the same ages and the body-weights were used. Throughout the experiments, I employed the following uniform technic for an injection into the subarachnoid space. The attached photographs will illustrate well the technic of injection. A glass syringe of one cubic centimeter size commonly used for a hypodermic injection was used. No anesthesia, local or general, was given to the animal. About $0.25 \mathrm{cc}$. of the liquid to be injected was put in a syringe, and with a needle fitted to it, a puncture was made into the cisterna magna through the atlanto-occipital membrane. On puncturing the cisterna, the cerebrospinal fluid flowed almost by itself into the syringe pushing out the pistonrod to a small degree, thus mixed with the liquid previously contained in the syringe. Waiting for a moment, until the flowing out of the cerebrospinal fluid hat ceased, injection was made gently and slowly into the subarachnoid space with a mixture of the cerebrospinal fluid and the liquid to be injected, in exactly the same amount as the cerebrospinal fluid which had come out into the syringe. Thus the utmost care was exercised not to disturb the equilibrium of a normal intracranial pressure.

At first, I laid the following plans of several experiments with the hope that, from their results, I might get some light in the right direction in arriving at the final solution of the problem under question.

1) A coloring solution is injected intravitally into the subarachnoid space. At a certain course of time after the injection, the labyrinthine fluid is obtained through the oval window, and is tested for its coloration by a macroscopic examination.

2) A chemical is injected intravitally into the subarachnoid space. At a certain course of time after the injection, the labyrinthine fluid is obtained through the oval window, and is tested for the chemical. (micro-chemical examination).

3). A histological examination is made on the petrous bone for the pathways in the labyrinth of the coloring fluid injected intravitally into the subarachnoid space.

As I have completed these experiments satisfactorily and have obtained the results which 1 believe are worthy to be put on record, I hereby report them in detail. 


\section{Experiment No. 1. \\ Experimental Studies with Macroscopical Examination.}

\section{Methods and Materials.}

In order to find a possible physiological communication between the cerebrospinal and the labyrinthine fluid, a certain coloring solution was injected into the subarachnoid space, and observation was made whether or not the coloring solution would appear in the labyrinthine fluid, the observation being made on the fluid oozed out through the opening of the oval window.

As a coloring solution, one per cent aquous solution of methylene blue was used. The opening of the oval window was made as follows:- The animal was fixed on an operating table. Under a routine surgical disinfection and under an infiltration anesthesia with a two per cent novocain solution, the front wall of the innermost part of the external auditory meatus was opened from outside, so as to get a full view of the tympanic membrane. The total tympanic membrane, as well as a small portion of the external bony wall of the epitympanic cavity was removed. Special care was exercised not to spoil the tympanic cavity with blood; even the slightest bleeding was checked in every step of the above operation. After the wound cavity was thoroughly dried, the maleus together with the incus was removed so cautiously as to cause no dislocation of the footplate of the stapes. Then the stapes was pulled out by grasping its head with a very delicate serrated forceps and moving gently to right and left. Thus it was not all a difficult matter to open the oval window with no accompanying injuries to the surrounding tissues.

An injection into the subarachnoid space with the coloring solution was of course made either before or after the removal of the stapes, as the case demanded.

\section{Results.}

1. When a methylene blue solution was injected into the subarachnoid space after the oval window had been opened and some cotton had been placed to this patent window, the cotton was seen stained by methylene blue immediately after the injection.

2. When the oval window was opened and this region was wiped with a cotton swab immediately after the injection of a methylene blue solution into the subarachnoid space, the swab was not stained by the first wiping, but stained by 
the subsequent wipings. In this case, if the oval window was opened a few minutes after an introduction of a methylene blue solution into the subarachnoid space, the swab was stained by the first wiping.

3. In the cases 1 . and 2., it was noticed that successive wipings with cotton swabs never made the patent oval window completely dry. After each wiping, the oval window became seemingly dry, but in a moment it became moistened with the lymph which oozed out rather profusely through the window.

4. If the oval window was opened two or three hours after the injection of a methylene blue solution into the subarachnoid space, coloration of the labyrinthine fluid could no more be observed.

\section{Discussion of the Results.}

Of the above results, the fact that the methylene blue solution appeared in the labyrinthine fluid almost immediately after it had been injected into the subarachnoid space would indicate sufficiently that the cerebrospinal fluid communicates freely physiologically, with the labyrinthine fluid, particularly with the perilymph. And I believe the fact that it was impossible to make the patent window completely dry by successive wipings with cotton swabs, each wiping being followed almost instantly by an oozing out of the lymph rather profusely through the oval window would doubly prove the existence of an easy communication between the cerebrospinal and the labyrinthine fluid. Unless we recognize the fact as above, an easy replenishment of the lymph after a moment's seeming dryness followed by wipings with cotton swabs cannot be explained.

In his paper on "The Studies of the Labyrinthine Fluid", Saito"1) says that the maximum amount of the labyrinthine fluid obtainable from an ear of a rabbit is but a very minute droplet. If it be really so, as he says, it should be said that the labyrinthine fluid is, at least, in a state either entirely shut off from, or very difficult to communicate with the cerebrospinal fluid. A great difference will then be found in the results of his experiment and of mine. I have made, however, a careful histological examination on the specimens taken from the animals killed immediately after the present experiment, have found no trace of injuries which had led to an establishment of communication between the cerebrospinal and the labyrinthine fluid. Therefore, I firmly believe in the correctness of the findings I obtained in the present experiment of my own.

Experiments similar to mine will be found in the literature in $1877-79$ by 
Weber-Liel $l^{24,30}$ and in 1923 by Chilozw. Both described that a coloring solution injected into the subarachnoid space was transmitted to the labyrinthine fluid by way of the aquaeductus cochleae. Weber-Liel used Beale's blue solution on a human cadaver, and Chilow used a methylene blue solution on a dead cat." There are no descriptions in their papers on the 'exact amount of the coloring solution introduced into the subarachnoid space. It seems probable, therefore, that they paid little attention to this particular matter. Accordingly, it is difficult to judge from the experiments of these predecessors that such relationship really existed between the two fluids in the living, or can exist only in the dead, or further whether the coloring solution was transmitted to the labyrinthine fluid through an artificial crevice at some part between the labyrinth and the intracranial cavities.

The present experiment of my own, I believe, makes up for what lacked in the experiments of both Weber-Liel and Chilow, and demonstrates, aside from a communication way, that the cerebrospinal fluid has an easy connection physiologically with the labyrinthine fluid.

\section{Experiment No. II.}

\section{Experimental Studies with Micro-chemical Tests.}

\section{Methods and Materials.}

A glucose solution or Presojod was injected into the subarachnoid space. At certain times after the injection, tee labyrinthine fluid as well as the cerebrospinal fluid was removed. The labyrinthine fluid was removed by introducing a capillary glass tube in the cisterna perilymphatica through the oval window, and the cerebrospinal fluid, by puncturing the cisterna magna. Micro-chemical tests were done on these fluids for the substance injected into the subarachnoid space.

It was proved by the preceeding experiment that, as soon as the oval window is opened, there comes out not only the labyrinthine fluid, but also the cerebrospinal fluid. Therefore,' special care was exercised in the present experiment, to obtain the labyrinthine fluid with no contamination of the cerebrospinal fluid. For this purpose, a great effort was directed to bring a capillary glass tube in the oval window at the very moment when the stapes was removed, and thus to get the very first drop of the fluid that came out, up in the tube. In order to attain this purpose satisfactorily, I employed many rabbits with normal hearing organs, of approximately the same ages and body-weights, and the rabbit; having had its 
labyrinthine fluid once taken, was never used again in the experiment. Thus erorneous results that might otherwise be possible were avoided to the greatest extent.

The glucose solution was prepared with distilled water and made isotonic with the body fluid of a rabbit (about six per cent), and before each time of injection the solution was warmed to the body temperature.

As a test for glucose, phenylhydrazin method was employed. One drop of the fluid to be tested and $0.5 \mathrm{cc}$. of distilled water were taken in a small test tube, and one drop each of phenylhydrazin and glacial acetic acid was added. The content was well mixed and heated for one hour on a boiling water-bath, and then allowed to cool down in a room temperature. The deposits which had collected at the bottom of the tube were removed with a pipette and examined under a microscope for the crystals of phenyglucosazon.

In order to know the limit of accuracy of the above phenylhydrazin method with which the content of glucose in the fluid can be tested qualitatively, a preliminary examination had been made with glucose solutions in different dilutions, and found that 0.000078125 gram of glucose in one drop (about $0.06 \mathrm{cc}$.) of the fluid, or $1 / 6400$ part of glucose in the mixture of one drop of the fluid and $0.5 \mathrm{cc}$. of distilled water can be demonstrated definitely by this method.

Presojod is a light yellowish, limpid watery liquid and contains $0.02-0.3$ per cent of free iodine. It, being originated by Professor Pregl of the University of Graz, Austria, is also called Pregl'sche Loesung.

At first, I used potassium iodide or sodium iodide, but as these exerted poisonous action on an animal when injected into the subarachnoid space, I gave them up. Satisfactory results, however, were obtained later by a trial of Presojod.

Qualitative Test for Presojod:- The qualitative test for free iodine contained in Presojod was applied to the demonstration of Presojod. A very small amount of starch and potassium nitrate, and one or two drops of the fluid to be tested were mixed on a slide, and then a drop of fuming sulphric acid was added to the mixture. The slide was brought under a microscope and the characteristic iodine reaction of the starch granules was examined. By repeated preliminary examinations, $0.0005859 \mathrm{cc}$. in one drop of the fluid to be tested had been found to be the minimum amount of Presojod which can be detected definitely by this method.

The glucose solution or Presojod inejected into the subarachnoid space by the way above described, gave no ill effects whatever to the animals. 


\section{Results.}

The results of the experiment are shown in the following table.

\begin{tabular}{|c|c|c|c|c|c|c|c|c|c|c|c|c|c|c|c|c|c|c|}
\hline \multirow{2}{*}{\multicolumn{2}{|c|}{ Fluid to be tested }} & \multicolumn{17}{|c|}{ Time after the injection into the subarachnoid space } \\
\hline & & $\begin{array}{l}\text { imme- } \\
\text { diate }\end{array}$ & $10 \mathrm{~m}$. & $30 \mathrm{~m}$ & $1 \mathrm{~h}$. & $1 \frac{1}{2} \mathrm{~h}$. & $2 \mathrm{~h}$. & $2 \frac{1}{2} \mathrm{~h}$. & $3 \mathrm{~h}$. & $3 \mathrm{~h}$. & $4 \mathrm{~h}$. & $4 \frac{1}{2} \mathrm{~h}$ & $5 \mathrm{~h}$. & $5 \frac{1}{2} \mathrm{~h}$. & $6 \mathrm{~h}$. & $8 \mathrm{~h}$. & $16 \mathrm{~h}$. & $24 \mathrm{~h}$ \\
\hline \multirow{2}{*}{$\begin{array}{l}\text { Cerebro- } \\
\text { spinal } \\
\text { fluid }\end{array}$} & Glucose & $H$ & H & + & + & + & + & + & + & + & - & - & - & - & - & - & - & - \\
\hline & Presojod & $H$ & $H$ & + & + & + & + & + & + & + & \pm & - & - & - & - & - & - & - \\
\hline \multirow{2}{*}{$\begin{array}{l}\text { Labyrin- } \\
\text { thine } \\
\text { fluid }\end{array}$} & Glucose & \pm & $H$ & + & + & + & + & + & + & + & - & - & - & - & - & - & - & - \\
\hline & Presojod & \pm & $H$ & + & + & + & + & + & + & + & \pm & - & - & - & - & - & - & - \\
\hline
\end{tabular}

1. Clucose as well as Presojod was demonstrated in the labyrinthine fluid most markedly in about ten minutes after it had been injected into the subarachnoid space, but later its appearance in the labyrinthine fluid became less marked as the time passed. And about four hours after the injection, glucose or Presojod became almost undetectable in the labyrinthine fluid.

2. In the cerebrospinal fluid, too, glucose or Presojod was demonstrated most markedly in ten minutes after it had been introduced into the subarachnoid space, and at the end of about four hours after the injection, it became almost undetectable.

\section{Discussion of the Results.}

The above results show, evidently, that the substance introduced into the cerebrospinal fluid in the form of solution, appears in the labyrinthine fluid in a few minutes, and disappears in several hours, and that the substance thus introduced into the subarachnoid space disappears from the cerebrospinal fluid almost simultaneously in several hours, the time in which it disappears from the labyrinthine fluid. These facts, therefore, indicate, not only that the cerebrospinal fluid has an easy communication physiologically, with the labyrinthine fluid, but also, that the perilym phatic spaces of the labyrinth form a one-piece lymph cavity and the drainage of these two fluids takes place in the same common way or, at least, in very closely related ways in some sense or other.

According to Szasz's view, ${ }^{25)}$ the lymph current between the labyrinthine and cerebrospinal fluids, if present, at all, must always be directed from the perilymph to the cerebrospinal fluid. However, the results of my present experiment would lead us to suppose that it is not always the case as Szasz imagines, but that the 
perilymph and the cerebrospinal fluid are in such a state that they may flow in either direction.

In connection with the present experiment, a question may naturally arise as to whether the cerebrospinal and the labyrinthine fluid of a normal rabbit may contain enough glucose or iodine to be detected by the methods applied in the present experiment. I examined a large number of specimens of the cerebrospinal and the labyrinthine fluids of normal rabbits, and found them always negative to both glucose and iodine when tested by the methods applied in the present experiment. I do not doubt, therefore, that this control examination guarantees the significance of the results obtained from the present experiment.

The results of two of my experiments have shown that the cerebrospinal fluid communicates freely with the labyrinthine fluid. We, therefore, must be exceedingly cautious in technic when obtaining the labyrinthine fluid or it will be contaminated with cerebrospinal fluid.

There is ample room to suspect previous observers were not sufficiently cautious in this respect, and $I$ therefore, am forced to doubt the value of their findings.

\section{Experiment. No. III.}

\section{Experimental Studies with Histogical Examinations.}

I undertook the following experiment in order to determine, by means of histological examinations, the pathways in the labyrinth of the coloring substance injected intravitally into the subarachnoid space.

At first, as the coloring substances, I used lithium carmine, trypan blue, Indian ink, and a ferrocyanicle solution, etc. I experienced, however, much disadvantage with lithium carmine and trypan blue, as these dyestuffs were easily subjected to decolorization by a process of decalcification. Therefore, subsequently I used Indian ink and a ferrocyanide solution exclusively. It may be noted here in this connection, however, that I have later been able to obtain positive findings in the intra vitam staining of the labyrinth of a rabbit, by injecting into the subarachnoid space lithium carmine, the details of which will be reported in another paper. ${ }^{14)}$

A ferrocyanide solution was once used by $W_{e e} d^{31)}$ of Harvard Medical School, Boston, in the studies of drainage of the cerebrospinal fluid, and was recommended by him as an ideal solution in a study of the pathways of body fluids. The solution was made up of potassium ferrocyanide and iron ammonium citrate in equal parts 
and in such concentration as to be practically isotonic with the body fluid. The solution gets into tissues as a true solution and can be precipitated subsequently in situ as the characteristic granules of Prussian blue by fixing the tissues with a fixative acidulated with hydrochloric acid. This, according to Weed, facilitates a subsequent histological examination of the pathways followed by the solution.

Indian ink is not a solution, but is really a suspension of insoluble carbon granules, while a ferrocyanide solution is a true solution. The physical nature of the two fluids is different. Having thought it would be instructive to make a comparative study on the pathways followed by fine insoluble particles and by a true solution, I employed to advantage these two fluids, a suspension of Indian ink and a ferrocyanide solution.

\section{A. Experiment with indian ink.}

\section{Materials AND Methods.}

A suspension of Indian ink was prepared by gently rubbing a stick of Indian ink on a smooth glass dish (Petri dish) with a normal saline solution. The suspension was filtered and sterilized.

An injection of the suspension into the subarachnoid space was made in one group of the animals, only once, while in the other it was repeated several times with certain intervals. No abnormalities were observed in the animals before and after an injection.

In order to make clear the timely relation of the pathways in the labyrinth of Indian ink injected into the subarachnoid space, the animals were sacrificed at definite periods of time after they had been injected into the subarachnoid space with a suspension of Indian ink; namely, immediately, thirty minutes, one hour, two hours, four hours, eight hours, sixteen hours, twenty-four hours, three days, one week, tivo weeks, four weeks, several months, after the injection.

In one group of the animals, vital fixing was applied. In another, the animals were killed by an air embolus. In the latter group, at first, the animals were immediately decapitated and the petrous portions with the labyrinth separated from the other parts were placed in a fixative. However, as I considered that, by this way, an escape of the cerebrospinal fluid, followed by a possible escape of the labyrinthine fluid might bring forth erroneous results in the experiment, I adopted subsequently the following procedures: In order to avoid an escape of the cere- 
brospinal fluid at the time of decapitation, 'immediately after an animal was killed and before decapitation; one or two upper cervical vertebrae were removed, care being taken not to injure the dura mater, and the spinal cord with its dura mater was ligated tightly en mass and the whole head, except the lower jaw was removed in 'one piece; the "skull 'cap was carefully rongeured away as widely as possible without disturbing the dura, and the middle ear bullae were widely opened; and the whole piece of the head was placed in a fixation solution, etc., as a routine process of making a histological specimen. After the complete embedding of a whole piece of head in celloidin, its petrous portions with the labyrinth were seperated from the other portions.

As a fixative, Wittmaack's fluid was used. For decalcification, a five per cent solution of nitric acid was employed.

All the specimens were cut serially in 15-25 microns. The sections were stained 'with hematoxyline and eosin as a routine. In some sections, staining with iron hematoxyline, van Gieson's method, alum carmine staining etc., was used.

\section{Results.}

By "Immediate, Thirty Minutes, One Hour, Two Hours, Short Time, Long Time, etc.," that is given below, is meant the histological speciments prepared from the petrous portions taken from the animals killed immediately, thirty minutes, one hour, two hours, short time, long time, etc., respectively after the injection into the subarachnoid space with a suspension of Indian ink.

Indian ink granules were found invariably in the perilymphatic spaces, but not in the least in the endolymphatic space in any specimen from "Immediate" to "Several Months".

In the Perilymphatic Spaces:- “Immediates:” in some, the granules were found densely throughout the entire perilymphatic spaces, while in others, they were found mostly in the scala tympani, but not in the rest of the perilymphatic spaces, vestibular or of semicircular canals. In the latter case, the granules in the scala tympani were found to be most marked in the basal whorl, especially in the neighbourhood of the round window, and the higher the whorl, the less became the granules until they disappeared in the region where Helicotrema Berschetti drifts to the scala vestibuli. The difference in the extension of Indian ink granules found in the perilymphatic spaces as above seems to be due to a possible difference in the amount of the Indian ink granules introduced into the subarachnoid spaces, as, in 
general, denser granules were found in the former than in the latter. Any specimens after "Thirty Minutes," however, showed the granules throughout in the perilymphatic spaces of the entire labyrinth, viz, of the cochlea, of the vestibule, and of the semicirular canals. (Fig. 2).

In an individual specimen, the granules were generally denser in the cochlea than in the vestibule, and less dense in the semicircular canals than in the vestibule. In the cochlea, they were denser in the scala tympani than in the scala vestibule. And in the scala tympani, they were most dense in the basal whorl, becoming less in the higher whorls, while in the scala vestibuli, the lower the whorl, the less they became. However, the granules might be found sometimes accumulated densely in an indefinite part and relatively sparse in other parts.

The granules found in "Short Times" were generally fine and they were suspended in the lumen, or attached to the walls of the perilymphatic spaces. In the vestibule and in the semicircular canals, they were also found attached to the trabeculae that traverse the perilymphatic spaces. But the granules found in "Long Times" were coarse, and located deeper in the surrounding tissues than in case of "Short Times", some being found in the blood capillaries, in the endothelial cells that line the perilymphatic spaces, or in the reticulum cells that form trabuculae in the perilymphatic spaces of the vestibule and the semicircular canals. In "Eight Hours", the granules were rarely found in the lumen in a free state, but mostly found as coarse granules in the endothelial cells, in the reticulum cells, in the connective tissue cells, in the perivascular lymph spaces or in the blood capillaries in the surrounding walls. In "Two Hours", the wandering cells filled with the granules were found attached to the walls or hemmed in the surrounding tissues of the perilymphatic spaces.

In the Ligamentum Spirale:- In "Short Times", the granules were found only along the rim which faces the scala tympani, or the scala vestibuli. In "Long Times", (rarely after "Four Hours", always after “One Week",) there could be found the granules all over the ligament, in which a granular accumulation was often noticed along the blood vessels, around the prominentia spiralis, especially about the vas prominentia spiralis, or in the stria vascularis, or along its lateral side. Not infrequently the granules were found phagocytosed in places in the ligament. No granules were ever seen, however, in the epithelium which lines the inner surface of the ligament facing the ductus cochlearis.

In the Lamina Spiralis : - In "Short Times", the granules were found only 
in the endothelium which faces the scala tympani. After Four Hours, it was found that the granules was gradually extended or shifted towards the membrana basilaris, and also towards the ganglion spirale along the fibers of the cochlear nerve than run through the lamina.

In the Limbus Spiralis:- The granules were often seen in the part which borders the scala vestibuli. In "Long Times", the granules became coarser and dispersed all over the limbus, often accumulating along the blood vessels. Phagocytosis was noticeable in places.

In the Membrane of Reissner:- The granules were seen in the endothelial layer which faces the scala vestibuli, but not in the epithelial layer which faces the ductus cochlearis. In "Long Time", the granules became coarse, collecting in groupes.

As has already been mentioned the membranous cochlea, including Corti's organ; the ductus cochlearis, in its lumen or lining epithelium ; the membrana tectoria, etc., showed no granules in any of the specimens.

In the Modiolus : - In “Twenty-four Hours ", there could be seen the granules in the blood vessels, in the perivascular lymph spaces, and along the fibers of the cochlear nerve located centrally to the ganglion spirale. In “One Month", the coarse granules engulfed in the ganglion cells of the ganglion spirale and in cells along the inner walls of the canalis spiralis of Rosenthal could be seen (Fig. 5.). No such findings were obtained in specimens before "Twenty-four Hours".

In the Vestibule and the Semicircular Canals : - It has already been described in the positive findings in the perilymphatic spaces, as well as in the negative findings in the endolymphatic spaces.

In the Maculae and the Cristae:- The submucosa was the only place in which the granules were seen. The granules were seen as finely divided deposits at first, but in "Four Hours", they showed coarser deposits, often accumulating beneath the basement membrane, among the nerve fibers, in the connective tissue cells, or in the endothelial cells of the blood vessels in the submucosa (Fig. 3). In "Twenty-four Hours", the granules could be traced along the fibers of the vestibular nerve (Nn. ampullaris, $\mathrm{Nn}$. untriculo-saccularis) from their terminal branches in the submucosae of the maculae and the cristae up to the internal auditory canal.

In the Auditory Meatus:- The granules were found in the epineurium and the perineurium of the eighthnerve, as well as among the vestibular ganglion cells. They were also seen in the perivascular lymph spaces or in the capillary vessels. 
The granules in the above parts were seen as fine granules at first, but with the passing of time, they became coarser or collected as masses, engulfed in the surrounding cells. There could be found no granules in the dura mater which lines the internal auditory canal. In "Twenty-four Hours" no evidence could be found that led us to suspect the transit of the granules from the internal auditory meatus to the interior of the labyrinth through the lamina cribrosa.

In the Saccus Endolymphaticus and the Aquaeductus Vestibuli : - In "Short Times", there could be found a somewhat marked collection of the granules just in the perilymph about the vestibular end of the aquaeductus vestibuli (Fig. 4), which, with the passing of time, could be traced, extending or shifting towards the saccus endolymphaticus along the perilymph space of the aquaeductus vestibuli. In "Three Days", the granules were found sparsely in the loose connective tissue about the saccus endolymphaticus. In "Short Times", the blood vessels and the perivascular lymph spaces about the vestibular end of the aquaeductus vestibuli contained a few granules.

In the Aquaeductus Cochleae:- In any specimen from "Immediate" to "Several Months", the granular occurence was constant in the aquaeductus cochleae, and in an individual specimen, it was more marked in this part than in any other parts of the labyrinth. The granules in the aquaeductus were seen detained, in large number, by the reticulum tissue in company with the blood vessels, and even in "Immediate", caught, more or less by the reticulum cells (Fig. 1). The reticulum tissue in the aquaeductus cochleae being especially dense near the scala tympani opening, the granular occurence in this part was marked as well. When, therefore, the thick granular deposits in this part were compared with the very thin deposits in the adjacent scala tympani, marked contrast could be found. Just as in the other parts, the granules in the aquaeductus cochleae, that had originally been very fime, became gradually coarser with the passing of time. In "Short Times", the granules were found in the meshes in the free state, but in "Eight Hours", those in the free state became very rare; most of them were found with in the reticulum cells and" the endothelial cells. In "One Month", it was found that all the granules were phagocytosed by the cells just mentioned, becoming coarse masses and less numerous than in "Short Times".

\section{Discussion of the Results.}

As shown in the above results, an Indian ink injected intravitally into the 
subarachnoid space in amounts so small as to cause no rise in the intracranial pressure, was able to reach the entire perilymphatic spaces of the labyrinth immediatly after the injection, while it never reached the endolymphatic spaces even several months after the injection. These facts, I believe, serve to prove fully the existence of a very easy communication between the cerebrospinal fluid and the perilymph of the imternal ear. But in regard to the communication of the cerebrospinal fluid with the endolymph, if deduced only from the above results, it must be said that communication between the two fluids is either very difficult, or is lacking entirely.

It was found firstly that Indian ink granules have been traced all the way through the aquaeductus cochleae to the entire perilymphatic spaces even immediately after the introduction of an Indian ink suspension into the subarachnoid space. Secondly, that there has been no evidence whatever that the Indian ink granules were transmitted from the subarachnoid space to the perilymphatic spaces by any other way than the aquaeductus cochleae, in the lapse of several months after the introduction of an Indian ink suspension into the subarachnoid space. From these two resuits it can be definitely said that the aquaeductus cochleae is the only passageway by which the cerebrospinal fluid communicates with the perilymph of the internal ear.

So far as I have been able to find in the literature, Wiitmaack $k^{3 i n}$ was the only one who described the histological findings of the labyrinth taken from the animal which had been injected intravitally into the subarachnoid space with Indian ink. He used cats for the experiment. According to his description, he could trace the Indian ink granules from the subarachnoid space to the entire course of the aquaeductus cochleae, but not farther up in the perilymphatic spaces of the labyrinth. There is a great difference between the results of Wittmaack's experiment and those of mine. This difference, I believe, was induced not by the use of a different kind of animal, but by the following few points that are imaginable regarding Wittmaack's experiment.

He injected Indian ink into the subarachnoid space in the posterior cranial cavity through the dura mater exposed by boring away a small portion of the skull. According to my experience, this method of injection is liable to cause leakage of the cerebrospinal fluid through the puncture hole of the dura mater, and consequently lowers the intracranial pressure. And, furthermore, by this method of injection, most of the liquid to be injected escapes backwards through the puncture of the dura mater, and therefore, not infrequently, too little liquid is really introduced 
into the subarachnoid space.

It is reported that Wittmaack's animals became very excitable and restless, and were often attacked by cramps and died of gradual weakness within two weeks after the animals had been injected with Indian ink into the subarachnoid space.

These untoward results to the animals of Wittmaack may have been due to the surgical interference used for the purpose of injection, as well as to the Indian ink suspension-Gruebler Burrische Tuschloesung used by Wittmaak. I may have contained, besides carbon granules, some irritating substance in the liquid component which was not only fatal to the animals, but also stimulated Wittmaack's so-called secretory process of the labyrinthine fluid, and thus prevented the Indian ink granules from reaching further up in the perilymphatic spaces.

My method in injection gives no surgical damage to the animals. A puncture with a small fine needle causes no leakage either of the cerebrospinal fluid or of the liquid to be injected, and thus makes it possible to regulate the amount of an injection liquid not to disturb an equilibrium of the normal intracranial pressure.

The Indian ink suspension used in my experiment was prepared with a normal saline solution. This suspension brought about no symptoms whatever to the animal, even if it were injected repeatedly day after day, and the animal remained perfectly normal after injection.

Such pathological changes in the labyrinth as observed in the Wittmaack's experiments were not found in any of the specimens in my experiment.

The method of injection and the suspension of Indian ink granules in a normal saline solution employed in this study of mine will, therefore, certainly afford no room for the adverse criticism that may be made for Wittmaack's experiments.

I observed, too, that when the amount of Indian ink introduced in the subarachnoid space was too small, the Indian ink granules could be traced through the aquaeductus cochleae only as far as to the scala tympani, especially in the neighborhood of the opening of the aquaeductus cochleae.

The fact that many of the Indian ink granules injected into the subarachnoid space were detained by the network of the reticulum tissue and the accompanying blood vessels in the aquaeductus cochleae, and that as early as immediately after the injection of Indian ink in the subarachnoid space, phagocytic phenomenon was observed to some extent in the reticulum cells and in the endothelial cells of the network, and that the density of the granules in the scala tympani was far less than that in the aquaeductus cochleae, would seem to indicate that the network in the 
aquaeductus cochleae plays an important role in the protection of the internal ear.

As already pointed out, generally in the specimens of "Sliort Time", there was seen gradual diminution or disappearance of the granular precipitates of Indian ink on tracing the precipitates from the aquaeductus cochleae to the perilymphatic spaces of the vestibule and the semicircular canals, all the way through the scala tympani upwards from its lowest point to the helicotrema, then the scala vestibuli downwards from its highest extreme to the vestibular perilymphatic cistern. And those precipitates that were at first found free in the lumen, or attached to the surrounding walls, or engulfed in the connective tissue cells or in the endothelial cells, or involved in the capillary blood vessels or the perivascular lymph spaces in the parietal tissues, became later hemmed in the deeper tissues along the blood vessels or the perivascular lymph spaces.

From these facts, it would seem certain that finely divided, non-poisonous, insoluble foreign bodies like carbon granules of Indian ink, in the course of their gaining way into the perilymphatic spaces from the subarachnoid space through the aquaeductus cochleae, are detained or absorbed, portion by portion, by the surrounding tissues, as well as by the reticulum tissue in the lumen, if present, as in the aquaeductus cochleae, the perilymphatic spaces of the vestibule and the semicircular canals, without inducing reactive inflammation of the tissues they passed by or through.

The fact that the granular material found at first exclusively in the bloodcapillaries and in the lymph spaces about the small blood vessels that are situated superficially in the surrounding tissues of the perilymphatic spaces were seen, with the passing of time, in the deeper tissues along these blood vessels and perivascular lymph spaces, would seem to us to prove that the Indian ink introduced into the subarachnoid space did not take its way into the labyrinth through the blood vessels or the perivascular lymph spaces, but took its way out through these vascular routes aften it had been admitted once to the perilymphatic spaces through the aquaeductus cochleae, and then absorbed in the surrounding tissues.

As described, while, in "Short Times", there was no evidence of the granular precipitates along the cochlear nerve fibers that run.through the modiolus, the appearance of the granules was demmonstrated among fibers of the same nerve passing through the lamina spirale. And the granules at the latter place could be traced, not only back towards the adjacent scala tympani, but also, with the passing of time, centrally, towards the internal auditory canal along the cochlear nerve fibers in the modiolus via the ganglion spirale. Frome these facts, it is evident that the 
perineural lymph spaces of the cochlear nerve did not admit the Indian ink introduced in the subarachnoid space, into the interior of the cochlea through the lamina cribrosa from the side of the internal auditory canal, but allowed the reverse passage of Indian ink which had been admitted from the subarachnoid space to the scala tympani through the aquaeductus cochleae and then absorbed to the perineural space of the cochlear nerve near its extreme end in the lamina spirale.

Just as in the case of the cochlear nerve, "in Short Times", no granules. were demonstrated along the vestibular nerve fibers that are situated in the bony capsule of the labyrinth interior to the lamina cribrosa, while a few granules were demonstrated among the nerve fibers that pass through the submucosa of the cristae ampullare or of the maculae acusticae. And the granules found among the nerve fibers of this submucosa could be traced back to the perilymphatic spaces of the vestibule and the semicircular canals, as well as later, towards the internal auditory meatus along the fibers of the same nerve. From these facts, it is evident that the perineural lymph spaces of the vestibular nerve, too, did not admit the Indian ink introduced in the subarachnoid space directly into the interior of the vestibule or of the semicircular canals through the lamina cribrosa from the side of the internal auditory meatus, but allowed the reverse passage of Indian ink which had been admitted to the perilymphatic spaces of the vestibule and the semicircular canals through the aquaeductus cochleae and the scalae in the cochlea, and absorbed to the perineural lymph spaces of the vestibular nerve in the submucosa of the cristae or of the maculae.

No evidence of granular deposits, in "Short Times", in and about the saccus and ductus endolymphaticus, except about the aquaeductus vestibuli, and subsequent extension or shifting of those about the latter part towards the saccus endolymphaticus with later precipitation in the loose connective tissue around it, prove that the Indian ink introduced in the subarachnoid space did not find its way into the labyrinth through the saccus endolymphaticus, but found its way out through the perilymphatic spaces of these organs from the side of the vestibule towards the intradural end of the saccus endolymphaticus, after it had been admitted to the perilymphatic spaces of the vestibule from the subarachnoid space through the aquaeductus cochleae and the scalae tympani et vestibuli. Incidentally, there was such finding as to suggest to us that the granules about the saccus endolymphaticus and the aquaeductus vestibuli would be carried out partly by the veins that follow the aquaeductus vestibuli, and partly by direct abserption into the venous sinus from the lymph spaces about the 
saccus endolymphaticus which is situated in close approximity to the sinus.

As already described, the Indian ink granules, once admitted to the perilymphatic spaces of the labyrinth after they had been injected into the subarachnoid space, remained in the labyrinth for months without being completely absorbed; and the granules that appeared at first as very finely divided particles became, with the passing of time, coarser and presented phagocytic phenomenon in places.

These facts would seem to indicate that the transmission of insoluble, nonpoisonous particles such as the carbon granules of Indian ink from the perilymphatic. spaces of the labyrinth to their outside through the blood vessels, perivascular and perineural lymph spaces was, by no means, carried out either solely by a lymph current, nor in the same velosity as a lymph current, but carried out gradually and slowly from one place to another by the process of phagocytic action of the endothelia cells, the fibrocytes and the wandering cells of the surrounding tissues.

The results of this experiment did not afford us any evidence of direct communication of the cerebrospinal fluid with the endolymph, as well as of a possible relation between the perilymph and the endolymph. The negative results on these connections, therefore, would certainly indicate the necessity of further studies. The results of the present experiment, however, would seem, at least, to suggest to us the posibilities of the following facts:-

1. There are no channels in the membraneous labyrinth through which the perilymph flows into the endolymph.

2. Foreign bodies like the carbon granules of Indian ink admitted to the perilymphatic spaces are absorbed in the surrounding tissues and carried out the labyrinth through the blood vessels, perivascular and perineural lymph spaces in such a way as to avoid their invading the membraneous labyrinth.

3. The communication of the perilymph with the endolymph is carried out either by a process of diffusion or by such a way that the endolymph flowes, in the main, outwards to the perilymph.

\section{B. Experiment with ferrocyanide solution.}

1. Materials and Methods.

Except the following few points of minor importance naturally connected with an employment of a ferrocyanide solution instead of a suspension of Indian ink, the experiment was carried out in exactly the same way as in the previous experiment $B$.

The ferrocyanide solution used in the present experiment was prepared with 
0.45 gram each of potassium ferrocyanide and iron ammonium citrate dissolved in one hundred cubic centimeters of distilled water. By a preliminary test with blood corpuscles of a rabbit and ferrocyanide solutions of different concentrations, I proved that the solution of this concentration was practically isotonic with the body fluid of a rabbit. Aseptically prepared, freshly filtered solution was always used.

As a fixative reagent, a ten per cent formaldehyde solution was used. But, for the first twenty-four hours, a ten per cent formaldehyde solution containing one per cent concentrated hydrochloric acid was used. For decalcification, a two per cent solution of hydrochloric acid was employed.

\section{Results.}

By, "Immediates, Thirty Minutes, One Hour, Two Hours,... S Short Time, Long Time, etc.," that is given below is meant the histological specimens prepared from the petrous portions taken from the animals killed immediately, thirty minutes, one hour, two hours, ...., short time, long time, etc., respectively after the injection inito the subarachnoid space with a ferrocyanide solution.

Of all the specimens in this experiment, the precipitates of Prussian blue were found to be most marked and their distribution was most extensive in the labyrinth in the "Immediates". With the passing of time, the precipitates became less marked and their distribution in the labyrinth became less extensive. In "Eight Hours", they were not found in any part of the labyrinth, except in the perineural lymph spaces of the eighth nerve that exists in the internal auditory meatus, even in which the precipitates were so slight that they could be detected only by the most careful searching. In "Twenty-four Hours", no precipitates could be found in any part in either the labyrinth or the intracranial cavity.

The detailed description of the positive findings will be given in the following:-

In the perilymphatic Spaces:- In some of the "Immediates", it was found that the Prussian blue granules were present in marked density in the perilymphatic spaces throughout the cochlea, the vestibule and the semicircular canals, while in the others, the granules could be traced continuously, but with gradual diminution until they disappeared anywhere on the way starting from the lowest extreme of the scala tympani to the perilymphatic spaces of the semicircular canals through the scala tympani upwards to the helicotrema, aud then through the scala vestibuli downwards to the cisterna perilymphatica vestibuli.

It was noted that these granular deposits in the perilymphatic spaces became 
rapidly less significant or became abruptly negative with the passing of time, from "Immediates" to "Thirty Minutes", "One Hour", "Two Hours" and so on. In "Four Hours", there could be seen no granules in any part of the perilymphatic spaces, except that a small number of granules was found in the scala tympani in the neighbourhood of the opening of the aquaeductus cochleae. In "Eight Hours", the granules were absolutely negative throughout the perilymphatic spaces.

As in the case of Indian ink, in an individual specimen, the Prussian blue granules were in general denser in the cochlea than in the vestibule, and again denser in the vestibule than in the semicircular canals. In the cochlea, they were denser in the scala tympani than in the scala vestibuli. And in the scala tympani, they were densest in the basal whorl, especially in the neighbourhood of the opening of the aquaeductus cochleae, and the higher the whorl, the less they became, while in the scala vestibuli, the lower the whorl, the less became the granules. However, thick collections of the granules might be found in one part with relative sparseness in the other parts. In "Short Times", the granular deposits were found to be partly free in the lumen, or attached to the surrounding walls, and partly in their lining tissues. Those in the lining tissues were found to be in the endothelial cells, in the connective tissue cells, or in the blood capillaries or the perivascular lymph spaces. In the perilymphatic spaces of the vestibule and the semicircular canals, the granules were found also in the trabeculae therein.

In "Long Times", the granules were not found in the lumen in a free state, but in the surrounding tissues as collected masses here and there.

In the Ligamentum Spirale :- In some of the "Immediates", there could be found the very finely divided precipitates diffusely throughout the ligament (Fig. $6)$, while in others, the occurrence of the granules was noted mostly in the lower whorls, and rarely in the upper whorls. In "Thirty Minutes", the granular occurrence in the ligament was also noted, but much less dense. In "Four Hours", the granules were present only in the ligament of the basal whorl, and none in those parts of the higher whorls. In "Eight Hours", no granules could be seen throughout the ligament.

Generally, the findings in the ligamentum spirale, as well as in the limbus spirale, the description of which will be given later, were noticed to be abreast of the occurrence of the granules in the scala tynupani or in the scala vestibuli. That is, when the granules were abundant in the perilymphatic spaces, they were also abundant in the adjoining part of the ligament or of the limbus, and when there 
were a few or none in the former, there would be a few or none in the latter.

The occurrence of the granular deposits in the ligament "was" diffuse in the form of finely dicided precipitates. A marked granular collection was often seen in and about the prominentia spirale, along the course of the blood vessels, and in the stria vascularis. A few granules were found, not only in the epithelium which covers the side of the ligament facing the ductus cochlearis, but also, sometimes, in the sulcus spiralis externus.

In the Limbus Spirale:- In "Immediates", the granules were seen as fine precipitates throughout the limbus. As in the ligamentum spirale, the marked collection of the granules was seen often about the blood vessels. Some of the granules were found in the cluctus cochlearis, as well as in the epithelium facing the ductus. In "Thirty Minutes", however, the granules becoming rapidly less marked, it became difficult to get the above findings.

In the Lamina Spiralis : - In "Short Time", the granules were found in the lining membrane of the scala tympani, beneath the basal membrane (Fig. 7). Very few granules were also found among the fibers of the cochlear nerve which pass through the spiral lamina, and in the ganglion spirale. The above findings became negative with the passing of time, as the granules in the scala tympani disappeared.

In the Reissner's Membrane:- The precipitates of Prussian blue were found in the endothelial layer of the side of the scala vestibuli in "Short Time".

In the Organ of Corti : - In the specimens before "Four Hours", some times there were present a few granules of Prussian blue in the cells of Deiter and of Hensen, in the tectorial membrane, and in the lumen of the ductus cochlearis (Fig. 7). But no such findings were obtained in the specimens after "Four Hours".

In the Modiolus: - A few granules were found scattered in the perivascular lymph spaces and in the blood vessels. These findings, however, were rarely obtained in the specimens after "Four Hours" and of "Immediates". In "Two Hours", a few granules were found occasionally among the fibers of the cochlear nerve that run through the modiolus and that are situated centrally to the ganglion spirale. These granules, being very faint, could be detected only by a careful examination. They were also very rarely found in the specimens either before or after this time.

In the Maculae Acusticae and the Cristae Ampullares:- In "Short Time", there could be seen fine granules diffuse in the submucosa. These granules were collected in places among the connective tissue fibers, about the vessels, in the capillary vessels, and most often beneath the basement membranes. A few granules 
were also found in the epithelium (Fig. 8). Moreover, the granules were also found aniong the nerve fibers in the submucosa, and in one case (two ears) out of five . (ten ears) of "Immediates" and in all cases of "Thirty Minutes ", a few granules; could be traced towards the internal auditory meatus along these fibers of the vestibular nerve (Fig. 10).

In the Internal Auditory Meatus:- Thick precipitates of finely divided granules were found in the epineurium, and among the nerve fibers and the vestibular ganglion cells. It was seen that the granules occurred, not only among the ganglion cells, but also in the cytoplasm of some of the ganglion cells. A marked granular collection was often seen about the blood vessels. No granules were found in the dural membrane which lines the internal auditory canal. A very few granules were sometimes found in small blood vessels.

The above findings became gradually insignificant, as the time passed. And in "Eight Hours", the granules became very few and faint, and occurred only in the epineurium of the eighth nerve. In "Sixteen Hour's", these granules became so faint as to be easily overlooked even by the most careful examination.. In the specimens after "Twenty-four Hours", the findings in the internal auditory meatus became negative.

As has already been stated, along the fibers of the cochlear nerve, no granules. were traced from the bottom of the internal auditory meatus towards modiolus, in the specimens before "Two Hours", while along the fibers of the vestibular nerve, a' few granules were traced from the bottom of the internal auditory meatus towards the periphery, in one instance out of five of "Immediates".

In the Aquaeductus Vestibuli and the Saccus Endolymphaticus:- There were found numerous fine granules of Prussian blue in the perilymph about the vestibular end of the aquaeductus and in the loose connective tissue about the saccus, especially on its cranial side in "Short Times" (Fig. 9). No granules were found, however, in the epithelial layer or in the lumen of these parts. A few granules were rarely found in the sinus which situates closely to the saccus.

In the Aquaeductus Cochleae:- There were seen numberless fine granules of Prussian blue throughout the aquaeductus cochleat. Many of these granules were either in a free state in or detained by the meshes of the reticulum tissue which accompanies the blood vessels. And not a few of these granules were also found to be in the cystoplasm of the reticulum cells or the endothelial cells of these meshes. Those granules that were in a free state in the meshes began to disappear in later 
specimens, and all the granules in the aquaeductus cochleae were found to be contained in the cells above mentioned. In one specimen, it was found that the precipitates of Prussian blue were more marked in the aquaeductus cochleae than in any other parts of the labyrinth. The precipitates in the aquaeductus cochleae could be traced to the subarachnoid space, in one way, and to the scala tympani and then to the entire perilymphatic spaces of the labyrinth, in the other way. The above findings became less marked in later specimens as in the other parts, and "Eight Hours", they became entirely negative.

\section{Discussion of the Results.}

It was proved by the present experiment that a ferrocyanide solution injected intravitally into the subarachnoid space in such a small amount as to cause no disturbance of equilibrium of a normal intracranial pressure, could almost in the moment of injection reach, not only all the perilymphatic, but also the endolymphatic spaces of the labyrinth. This fact, I think, would certainly indicate that the cerebrospinal fluid not only communicates freely with the perilymph, as has been proved by the preceeding experiment, but also has, normally, a close relationship with the endolymph.

In view of the fact that the precipitates of Prussian blue were traced all the way through from the subarachnoid space to the aquaeductus cochleac, the scala tympani, the scala vestibuli, the cisterna perilymphatica vestibuli, and the perilymphatic spaces of the vestibule and the semicircular canals, in "Immediate", it would be certain that the aquaeductus cochleae was the passage-way through which the ferrocyanide solution was transmitted from the subarachnoid space to the perilymphatic spaces of the labyrinth.

As has been stated above, the results of the present experiment showed that (1) in "Short Times", (up to one hour after the injection), there were no granules of Prussian blue along the fibers of the cochlear nerve between the ganglion spirale and the bottom of the internal auditory meatus, in spite of the very marked precipitates of Prussion blue that were found along the fibers of the same nerve situated in the internal auditory meatus, and also along those situated peripherally to the spiral ganglion and running through the spiral lamina; (2) in "Longer Times" (mostly two hours after the injection), the said precipitates, though few in rumber, could be found along the fibers of the cochlear nerve that pass through the modiolus, and in the ganglion spirale. These facts would be sufficient to prove that the 
ferrocyanide solution injected into the subarachnoid space did not take its way into the labyrinth through the perineural lymph spaces of the cochlear nerve from the side of the internal auditory meatus, but took the reverse way.

There were found in one of "Immediates" the precipitates of Prussian blue along the fibers of the vestibular nerve situated peripherally to the bottom of the internal auditory meatus, and along those situated in the internal auditory meatus. This finding, I consider, would naturally lead us to suspect that the ferrocyanide solution injected into the subarachnoid space could enter into the labyrinth through the perineural lymph spaces of the vestibular nerve from the side of the internal auditory meatus. And this suspicion would seem more probable when we take into account the very shortness of the vestibular nerve peripherally to the bottom of the internal auditory meatus, in comparison with the cochlear nerve, and also the difference in the other anatomical situation of the vestibular and the cochlear nerve. Therefore, if these factors are taken into consideration, it may not be wrong to presume that the vestibular nerve, unlike the cochlear nerve, could permit the passage of a ferrocyanide solution through its perineural lymph spaces into the labyrinth from the side of the internal auditory meatus.

However, it was only one case out of five that we found in "Immediates" the precipitates of Prussian blue among the fibers of the vestibular nerve situated in the bony capsule at the bottom of the internal auditory meatus. And such a finding was not obtained in the other four cases. Accordingly, we would rather be lead to believe that the transmission of a ferrocyanide solution into the labyrinth from the side of the internal auditory meatus through the perineural lymph spaces of the vestibular nerve would be either very difficult or impossible, just as it was the case in the cochlear nerve. Nevertheless, with regard to the above points, it would be impossible for us to draw any conclusion, unless we have get some other evidence. These points will, therefore, be discussed again in the later paragraph with the other experiment.

The appearance of the granular material in the loose connective tissue, especially, along the small blood vessels, about the saccus endolymphaticus in "Immediates", cannot be regarded as evidence that the ferrocyanide solution injected into the subarachnoid space took its way into the labyrinth through this part. Because, the acceptance of such a passageway affords much contradiction to the explanation from the histo-anatomiçal view-point. And because, in the other experiment, in which a ferrocyanide solution was injected intravenously on rabbits and guinea pigs; I was 
able to find the granular material in the loose connective tissue and along the small blood vessels about the saccus endolymphaticus, while the rest of the labyrinthine structures was entirely negative. In accordance with these facts; as well as with the fact proved by the previous experiment with Indian ink, the granules of Prussian blue that were found about the saccus endolymphaticus in the present experiment has another explanation, i. e., an indication that the ferrocyanide solution injected into the subarachnoid space could reach about the saccus endolymphaticus mostly. from within the labyrinthine cavity through the lymph channels about the aquaeductus vestibuli and the ductus endolymphaticus, after it had once been admitted to the cisterna perilymphatica vestibuli by way of the aquaeductus cochleae and the scalas of the cochlea, and in part, secondarily, from the vascular route.

The fact that the numerous granules of Prussian blue were found along the endosteal blood vessels in the surrounding walls of the perilymphatic spaces, about the small blood vessels in the spiral ligament, in the spiral limbus, and in the submucosae of the maculae and the cristae, as well as about the blood vessels in company with the eighth nerve, in the internal auditory meatus, in "Immediates", may lead us to suspect the entrance of a ferrocyanide solution into the labyrinth from the subarachnoid space through these perivascular routes. However, this suspicion is said to be unfair, because there were found no granules of Prussian blue in the perivascular lymph spaces situated in the bony capsule, an intermediate part between the bottom of the internal auditory meatus and the lining tissues of the labyrinthine cavities, in "Immediates", and because the granules found at first about the small blood vessels in the lining tissues of the labyrinthine cavities in time, were found in the deeper tissues along these blood vessels, while the granules in the internal auditory meatus were not followed towards the interior of the labyrinth beyond the lamina cribrosa. It would be quite certain, therefore, that the ferrocyanide solution introduced into the subarachnoid space, did not enter the labyrinth through the perivascular lymph spaces, but took its way out through these perivascular routes, after it had once been admitted to the perilymphatic spaces through the aquaeductus cochleae.

As has been pointed out, there was left a doubt, in the present experiment, on the possibility of admission of a ferrocyanide solution into the labyrinth through the perineural lymph spaces of the vestibular nerve from the side of the internal auditory meatus. Therefore, it cannot be said that the aquaeductus cochleae was the only passageway through which a ferrocyanide solution got into the labyrinth 
Irom the subarachnoid space. Nevertheless, I believe that the results of the present experiment fully prove that the aquaeductus cochleae is the main passageway, if not the only way, through which the admission of a ferrocyanide solution passes from the subarachnoid space to the labyrinth.

As to the importance of the reticular tissue in the aquaeductus cochleae for the protection of the internal ear, and as to the manner in which a ferrocyanide solution was transmitted from the subarachnoid space to the labyrinth through the aquaeductus cochleae, the same thing may be said here that has been considered in the previous experiment with Indian ink.

In the previous experiment with Indian ink, no positive proof was obtained that indicated the existence of a communication between the cerebrospinal fluid and the endolymph. In the present experiment, however, there was evidence to prove that a ferrocyanide solution was transmitted by diffusion to the endolymph through the epithelium of the membraneous labyrinth, especially, through that of the ligamentum spirale, the limbus spirale, the maculae and the cristae, as there were found numerous fne precipitates of Prussian blue in the ligamentum spirale, the limbus spirale, the submucosae of the maculae and of the cristae, as well as a few of the precipitates in the corresponding epithelium and in the adjacent endolymphatic spaces of the above structures. Therefore, the results of the present experiment would certainly indicate that the perilymph communicates with the endolymph through the epithelium of the membraneous labyrinth, and consequently, the cerebrospinal fluid communicates with the endolymph indirectly through the perilymph, and that such communication between the perilymph and the endolymph takes place by a process of diffusion.

As already stated, it was found that the carbon granules of Indian ink, when admitted once to the perilymphatic spaces of the labyrinth, remained there for months without being completely absorbed. But, in the case of a ferrocyanicle solution, quite a different feature was observed. The granules of Prussian blue were reduced rapidly with the passing of time, from "Immediates" to "Two Hours", and in "Four Hours", only a very few of the granules were found in the surrounding tissues of the perilymphatic spaces, and in "Eight Hours", no granules were found in any part of the labyrinth, except a very few, insignificant granules in the perineural lymph spaces of the eighth nerve situated in the internal auditory meatus, and in "Twenth-four Hours", the granules disappeared completely from the labyrinth. It was found that the granules in the subarachnoid space were reduced or disappeared almost in paralle with the reduction or disappearance of the granules in the laby- 
rinth. Thus, it was seen that only a very short time was required for drainage of a ferrocyanide solution from the labyrinth as well as from the subarachnoid space: From these facts, in contrast with the results of the previous experiment with Indian ink, it would seem most probable that absorption and drainage of a ferrocyanide solution had a close relationship with absorption and drainage of the cerebrospinal fluid. And, therefore, the above results with a ferrocyanide solution would, I think, furnish us some evidence to understand the physiological lymph current of the cerebrospinal fluid and the labyrinthine fluid.

\section{Injection of Coloring Substance into the Subarachnoid Space, Plus Opening of a Part of Labyrinthine Cavity.}

In experiment No. A, I was able to prove that Indian ink introduced into the subarachnoid space passed through the perineural lymph spaces of the cochlear nerve, as well as of the vestibular nerve centripetally from within the labyrinth towards the internal auditory meatus, but did not pass through the same in the reverse direction, that is, from the internal auditory meatus towards the interior of the labyrinth, beyond the lamina cribrosa. And, in the experiment No. B, I was able to prove further that a ferrocyanide solution injected into the subarachnoid space passed through the perineural lymph spaces of the cochlear nerve in the same way as was the case with Indian ink. However, with regard to the passage of a ferrocyanide solution through the perineural lymph spaces of the vestibular nerve, I obtained results which roused a little suspicion as to the possibility of such a passage from the internal auditory meatus to the interior of the labyrinth beyond the lamina cribrosa. I asked myself the following questions:

(1) If insoluble particles, like carbon granules of Indian ink, when injected intravitally into the subarachnoid space, invariably get into the perilymphatic spaxes of the labyrinth or whether they are sometimes admitted to the labyrinth through the perineural lymph spaces of the acustic nerve from the internal auditory meatus, beyond the lamina cribrosa?

(2) Might not a solution of ferrocyanide (as used in my experiment) injectod intravitally into the subarachnoid space, pass, by osmosis, via the perineural lymph spaces of the acustic nerve, from the internal auditory meatus to the labyrinth beyond the cribrosa?

(3) Whether there is not a difference in behavior of the lymph flow in the perineural lymph spaces of the cochlear nerve from that of the vestibular nerve, in 
respect to the passage of ferrocyanide solution.

To solve these questions, I carries out the following experiment in accordance with the facts proved by the previous experiments that there is a free communication between the cerebrospinal and the labyrinthine fluid, and that the labyrinthine fluid, made to flow out by the opening of a part of the labyrinthine cavity, can, at no time, be replenished by the cerebrospinal fluid.

It can easily be understood that, if there were a free passage-way in the perineural lymph spaces of the acustic nerve, through which the cerebrospinal fluid could flow in the direction from the internal auditory meatus to the labyrinth, the flowing out of the labyrinthine fluid in the tympanic cavity on the opening of a part of the external wall of the labyrinthine cavity should disturb the normal current of the fluid, and consequently would encourage the entry of the cerebrospinal fluid into the labyrinth through the perineural lymph spaces of the acustic nerve, at least at the moment of the opening of the labyrinthine cavity.

From this point of view, I considered that, by carrying out an experiment in such a way as to open a part of the external wall of the labyrinthine cavity at the moment of an introduction of a coloring substance into the subarachnoid space, I might get results different from those obtained in the previous experiment $\mathrm{A}$ or $\mathrm{B}$, in which an introduction of a coloring substance was not accompanied by the opening of the labyrinthine cavity.

\section{Materials and Methods.}

Except that the opening of the oval window was made at the moment when the coloring substance was injected into the subarachnoid space, the present experiment was carried out in the same way as was done in experiment $A$ and $B$.

In the opening of the oval window, the technic already described in experiment No., 1 was employed. As a coloring substance, an Indian ink suspension, as well as a ferrocyanide solution, used in the previous experiments $A$ and $B$, was employed.

In the previous experiments, it was proved the absorption and drainage of a fenrocyanide solution, unlike that of an Indian ink suspension, to be very quick, and therefore, I tried to get the specimens immediately after the above operation, in the experiment with a ferrocyanide solution, considering that a delay after the operation might bring forth erroneous results. However, in the experiment with Indian ink, I tried to obtain the specimens immediately, one hour, and several hours, after the operation. 


\section{Results.}

To avoid complication, only the characteristic findings, in contrast to those shown in the previous experiments $\mathrm{A}$ and $\mathrm{B}$, will be described.

\section{A. Results of the experiment with Iudian ink.}

(1) In all the specimens, there were found very marked precipitates of Indian ink granules in the aquaeductus cochleae, in both scal of the cochleae and in the cisterna perilymphatica vestibuli. The precipitates in these parts were so marked as to be easily visible to the naked eye. Despite the very marked precipitates in the above parts, the findings in the domain of the vestibule and the semicircular canals were entirely negative.

(2) In the specimens, in which the oval window was opened, but the membraneous labyrinth was not injured, there were present no granules of Indian ink in the endolymphatic spaces throughout.

(3) In the specimens, in which the oval window, as well as the external wall of the saccule were opened, the granules of Indian ink were found in the saccule, especially in the neighbourhood of the injured part, but not in the other endolymphatic spaces.

(4) In no specimens, were there found any granules of Indian ink in the perineural lymph spaces of the acustic nerve, either cochlear or the vestibular nerve, situated peripherally to the bottom of the internal auditory meatus.

(5) In no specimens, were there found any granules in the domain of the saccus endolymphaticus.

\section{B. Results of the experiment with a ferrocyanide solution.}

(1) Very thick precipitates of Prussian blue in the aquaeductus cochleae, in both scalas of the cochlea and in the cisterna perilymphatica vestibuli, in contrast to the complete absence of the precipitates in the domain of the vestibule (except the cisterna perilymphatica) and semicircular canals (including the maculae and the cristae), were the most characteristic findings in all the specimens. The Prussian blue precipitates in the former parts were so thick that they could be easily recognized to the naked eye.

(2) In the cochlea, the thick precipitates of Prussian blue were found not only in the entire scala, but also throughout the ligamentum spirale, the limbus spirale, 
and the lamina spiralis (but not in the basal membrane). Keeping abreast of the thick precipitates in these parts, the occurrence of the Prussian blue granules was found to be also marked in the lining epithelium, belonging to the ligamentum spirale and the limbus spirale, as well as in the lumen of the ductus cochlearis.

Generally, the occurrence of the precipitates in the cochlea and in the aquaeductus cochleae was far more marked than that observed in the specimens of experiment $B$.

(3) In addition to the above findings, in the specimens in which the oval window, as well as a part of the external wall of the saccule was opened, there were found the granules of Prussian blue in the saccule.

(4) The granules found abont the saccus endolymphaticus in experiment B, did not occur in the present experiment.

(5) In no specimen either with the opening of the oval window, or with the opening of the oval window and the external wall of the saccule, were there found any granules of Prussian blue along the fibers of the cochlear and the vestibular nerve, running through the bony capsule at the bottom of the internal auditory mentus.

\section{Discussion of the Results.}

The present experiment was carried out in such a way that the injection of a coloring fluid- an Indian ink suspension or a ferrocyanide solution, into the subarachnoid space, was accompanied by the opening of the oval window alone or of both the oval window and the external wall of the saccule. We could get us evidence of the entry of the injected fluid into the labyrinth from the side of the internal auditory meatus, through either the cochlear or the vestibular nerve, beyong the lamina cribrosa.

In the previous experiment No. III. B., in one case out of five of "Immediate", we found the granules of. Prussian blue among the fibers of the vestibular nerve, running through the bony capsule at the bottom of the internal auditory meatus, and raised a suspicion about the possibility of entry of a ferrocyanide solution into the labyrinth from the side of the internal auditory meatus through the perineural lymph spaces of the said nerve.

In the present experiment, however, in any case, either with the opening of the oval window alone or with the opening of both the oval window and the external wall of the saccule, we could not demonstrate the granules of Prussian blue 
among the fibers of the vestibular nerve peripherally to the bottom of the internal auditory meatus, as well as in the domain of the vestibule and the semicircular canals, except in the cisterna perilymphatica vestibuli and in the neighbourhood of the injured part of the saccule. I believe that this fact would certainly indicate difficulty of the passage of a ferrocyanide solution through the perineural lymph spaces of the vestibular nerve from the side of the internal auditory meatus to the labyrinth.

Therefore, if we compare the present results with those of the previous experiment No. III. B., we come to the conclusion that the ferrocyanide solution precipitated as the granules of Prussian blue among the fibers of the vestibular nerve, running through the bony capsule at the bottom of the internal auditory meatus in one of "Immediate" of the experiment No. III. B., came not from the side of the internal auditory meatus, but from the perilymphatic spaces of the vestibule and the semicircular canals, taking the roundabout way of the aquaeductus cochleae and the scalas of the cochlea.

I believe that the negative findings of the granular material, especially that of Prussian blue, in the region of the saccus endolymphaticus, give a sound basis for what I discussed in experiment No. III. B., as they would certainly indicate that a disturbed current of the labyrinthine fluid and a lowered pressure in the labyrinthine cavity and the subarachnoid space, induced by the opening of the oval window or of both the oval window and the external wall of the saccule, not only made a coloring fluid (an Indian ink suspension or a ferrocyanide solution) difficult to reach this region from the vestibule, but also prevented, to some extent, the absorption of the fluid into the vascular and the perivascular systems.

It requires no argument that the results of the present experiment indicate very clearly that the aquaeductus cochleae is the passageway through which the coloring fluid injected into the subarachnoid space gets into the labyrinth.

I believe that the following answers can be given to the questions in mind at the beginning of the present experiment:

1. Either the perineural lymph spaces of the cochlear nerve, or those of the vestibular nerve do not permit the passage of insoluble particles, like the carbon granules of Indian ink, but also of a true solution of osmotic equivalent to body fluids, like the ferrocyanide solution used in my experiments, when injected intravitally into the subarachnoid space.

2. It seems that there is no difference between the cochlear and the vestibular 
nerve, in respect to the passage of a ferrocyanide solution through their perineural lymph spaces.

\section{Summary.}

All of my experiments were carried out with a uniform technic i. e., injection into the subarachnoid space with different kinds of fluids on healthy rabbits with normal hearing organs.

In experiment No. 1, a dilute aquous solution of methylene blue was injected into the subarachnoid space, and observation was made on the fluid oozed out through the opening of the oval window, in order to find whether or not the solution would appear in the labyrinthine fluid. In this way, I found that the solution appeared in the labyrinthine fluid almost at the moment of injection, and knew a free communication existed between the cerebrospinal and the labyrinthine fluid.

In experiment No. II, the cerebrospinal fluid, as well as the labyrinthine fluid was removed at definite times after the injection of an isotonic glucose solution or of Presojod into the subarachnoid space, and micro-chemical tests were done on these fluids for the injected solution (glucose or iodine). In this way, I found that glucose or iodine appeared in the labyrinthine fluid most markedly in about the minutes after its introduction into the subarachnoid space, its appearance became gradually less marked until it disappeared in about four hours, the solution thus introduced into the subarachnoid space (glucose or iodine) disappeared from the cerebrospinal fluid in about four hours, almost abreast of its disappearance from the labyrinthine fluid. From these facts, I further knew the communication between the cerebrospinal and the labyrinthine fluid to be very free, and the perilymph to be, at least, a part of the cerebrospinal fluid.

In experiment No. III, by a through histological examination on a large number of the specimens of the petrous portions taken from the rabbits killed at different times after the injection of an Indian ink suspension or an isotonic ferrocyanide solution into the subarachnoid space, or after such an injection was accompanied by an artificial opening of a part of the labyrinthine cavity, the pathaways in the labyrinth of the said coloring fluid (Indian ink or a ferrocyanide solution) were studied very carefully. In this way, I could give, not only histological evidence for the results of experiments No. I and No. II, but also made out the facts summed up in the following.

1. When a coloring fluid was injected into the subarachnoid space, it was 
transmitted immediately into the labyrinthine fluid, by way of the aquaeductus cochleae, However, (a) an Indian ink suspension was transmitted only to the perilymph, and not to the endolymph. (b) A ferrocyanide solution, a true solution, was transmitted not only to the perilymph, but to the endolymph. The transmission to the endolymph took place indirectly through the perilymph by a process of diffusion, which seemed to occur through the epithelium of the membraneous labyrinth, especially through that of the ligamentum spirale, the limbus spirale, the maculae acusticae, or the cristae ampullares.

2. The pathways through which the coloring fluid injected into the subarachnoid space come into the labyrinth and out therefrom were.

(a) At first, the fluid got into the scala tympani of the basal whorl of the cochlea through the aquaeductus cochleae, and ascended the scala tympani to the helicotrema, descended the scala vestibuli to the vestibular perilymphatic space, and from there reached all perilymphatic spaces of the semicircular canals on one side, and the surrounding of the saccus endolymphaticus along the outside of the aquaeductus vestibuli and the ductus endolymphaticus on the other side. A ferrocyanide solution was also transmitted, in part, to the endolomph by diffusion.

(b) The fluid reaching the above parts was absorbed in the surrounding tissues and was carried out partly through the venous system, partly through the perivascular system and partly through the perineural lymph spaces of the acustic nerve.

However, the carbon granules of Indian ink (non-poisonous, insoluble particles) when once admitted to the perilymphatic spaces of the labyrinth were detained by the endothelial cells, the clasmocytes, the reticulum cells, the adventitia cells and the fibrocytes, etc., and remained for months without being completely absorbed, while a ferrocyanide solution, a true solution, was completely absorbed in several hours.

3. Neither an Indian ink suspension, nor a ferrocyanide solution, injected into. the subarachnoid space, was proved to enter from the internal auditory meatus into the labyrinth through the perineural lymph spaces of the acustic nerve, beyond the lamina cribrosa.

4. No coloring fluid, injected into the subarachnoid space, was proved to get into the labyrinth through the perivascular lymph spaces, or by way of the saccus endolymphaticus and the aquaeductus vestibuli.

As has already been mentioned at the beginning of this paper, in the literature, there are no concrete proofs regarding the real existence of a physiological communi- 
cation between the cerebrospinal and the labyrinthine fluid, and there are, as a matter of course, widely devergent views regarding the passage ways through which the two fluids communicate.

The experiments of mine, I believe, have brought out strong evidence to settle the pending questions on the physiological relation between the two fluids and on their communication ways.

From my experiments, I have come to the opinion that, in the treatment of the diseases of the internal ear, an excellent result, which otherwise is impossible, may be obtained by introducing medicaments into the subarachnoid space (or by tapping the cerebrospinal fluid). I hope the day will soon come when this method will come into practical use in otological therapeutics.

\section{Conclusions.}

1. Physiologically, there is a free comnunication between the cerebrospinal and the labyrinthine fluid. And it can be said that, at least, the perilymph of the labyrinth is a part of the cerebrospinal fluid.

2. The pathway through which the cerebrospinal fluid communicates with the labyrinthine fluid is the aquaeductus cochleae. .

3. There is no direct communication between the cerebrospinal fluid and the endolymph of the labyrinth, but they communicate with each other through the medium of the perilymph. A communication between the perilymph and the endolymph takes place by a process of diffusion, which seems to occur through the epithelium of the ligamentum spirale, the limbus spirale, the maculae acusticae or the cristae ampullares.

4. The entry of the cerebrospinal fluid from the side of the internal auditory meatus into the labyrinth through the perineural lymph spaces of the acustic nerve is either very difficult or impossible. On the contrary, the labyrinthine fluid easily passes out through the perineural lymph spaces of the acustic nerve.

Besides the above, I have studied the relation between the cerebrospinal and the labyrinthine fluid in cases of meningeal labyrinthitis, induced experimentally on rabbits. The paper is to appear shortly. 


\section{Bibliography.}

1) Baßinski, quoted by Barany (2).

2) Maramy. Centralbi. f. O. p. 342 1908-9.

3) Dtophm \& Davidorf, Lehrbuch der Histologie des Menschen p. 368 1898; p. 3721903.

4) Boenuinsmatis. Lehrbuch d. Ohrenhlkd. p. 2861908.

5) Chilow (J.). "Zur Frage der Ausgleichung des Labyrintbdruckes" Ztschr. f. H-N.O. Bd. 5 p. 404 1923.

6) Neisehmann (otto), "Studien über die Herkunft des Labyrinthwassers" Arch. f. O-N-KK. Bd. 120 p. 1931918.

7) Hasse (C.), “Bemerkungen über die Lymphhahnen des inneren Ohres" Arch. f. O. 18 p. 1881881.

8) Tennebert (Bruesel), Centrabl. f. O. Bd. 2 p. 161904.

9) IIyrt1, Zergliederungskunst p. 473-4 1860 .

10) Hyrt, Lehrbuch der Anatomie p. 6211881.

11) Crawn (T.), "Experimental studies on the appearance of the antibody in and its disappearance from the cerebrospinal fluid under various conditions" (Japanese) Kyoto, Ig. Z. Vol. 17 No. 101920.

12) Karlefors (John). "Die Hirnhautraeume des Kleinbirns, die Verbindungen des 4. Ventrikels mit den Subarachnoidalraeumen u. der Aqnaeductus cochleae beim Menschen" Acta Oto-laryngologica (Supplementum) IV. 1924.

13) Key \& Retzins, "Studien in der Aatomie des Nervensystems u. des Bindegewebes" Stockholm 1875.

14) Kibata ('T.), "The intra vitam staining of the internal ear".

15) Koelliker (A.), Handbuch der Gewebeslehre des Menschen Bd. 11. p. 9451902.

16) Knzume (G.), "Syphilitic labyrinthitis treated by Swift-Ellis" method" (Japanese) D. Ni. Jibi Inkokwa Kw. K., Tokyo, Bd. 23 p. 2731917.

17) Rejtoe (Alexander). "Über des Fluessigkeitssystem des Labyrinthes" M. f. O. Bd. 55 H. 4 p. 324 1921 .

18) Retzius, Das Gebörhrorgan der Wirbeltiere Bd. 11. p. $330 \& 277$ 1884, quoted by Fleischmann (6) p. 194: Siclenmann (22) p. 303 ; Karlefors (12); Rejtoe (17) p. 327.

19) Ruedinger, "Über den Aquaeductus vestibuli des Menschen und des Phyllodactylus europaeus" Ztschr. f. Anat. u. Entwicklungsgesch. Bd. $11187 \%$.

20) Rnedinger, "Die abruges Kanaele der Endolymphe" Münch. m. W. p. 1391888 (quoted hy Gray's Anatomy p. 847; Schwartze's Handbuch d. O. p. 133; Jacobson u. Blau's Lehrbuch d. Ohrenhlkd. p. 15; Bezold's Lehrbuch d. O. p. 17 etc.).

21) Snito (w.). "Studies on the labyrinthine lymph" Japanese) Kyoto Oto-Rhino-Laryngol. Klinic, Bd. 15 p. 5501923 .

22) Siebemmann (F.) Bardelebens Handbuch der Anatomie des Menschen (Sinnesorgan) Bd. V Abt. 11. p. $303-316$ p. 3221897.

23) Siebenmann (F.), "Anatomische Untersuchungen iiber den Saccus und Ductus endolymphaticus beim Menschen" Beitr. z. Anat. d. O-N-H. Bd. 13 Part 11. p. 591919.

24) Sehwahk" (G.). "Der Arachnoidalraum ein Lymphraum und sein Zusammenhang mit dem Perichorioidalraum" Centralbl. f. m. Wissenschaft. No. 30 p. 465-7 1869.

25) Szasz (T.), "Beiträge zur Iabyrinthliquorfrage" Ztschr. f. H-N_O. Bd. VI p. 2561923.

26) Takamori (T.). "The vital staining of the hearing organ" (Japanese) Kyoto, Ig. Kw. Z. Bd. 171920.

27) Tsnchiya (s.), "Experimental studies on the appearance of drugs in the human cerebrospinal fuid" (Japanese) Shinkei Gaku Z. Pd. 20 p. 971921.

28) Washimi (ac.), "Effect of Swift-Ellis' treatment on labyrinthine syphilis" (Japanese) D. Ni. Jibi Inkokwa Kiw. K., Tokyo, Bd. 23 p. 2781917.

29) Weber-Liel, Centralbl. f. a. med. Wissenschft. 1877.

30) Weber-Liel, "Experimentelle Nacliweis einer treien Communikation der endo- u. perilymphatischen Raemme des measchlichen Ohrlabyrinthes mit extralabyrinthischen intracraniellen Raeumen" Virchow's Archiv Bd. 77 p. 2071879 
31) Weed (I. H.), "Studies on the Cerebrospinal fluid $\&$ its pathway" $\mathrm{g} . \mathrm{m}$. Rnsearch Vol. XXXI $\mathrm{p}$. 24-49 1:914.

32) Weill (G. A.), Barre \& Castinel: Centralbl. f. O. p. 101, 1909-10.

33) Wittmanek (K.). “Experimentelle Studien über die Beziehungen der Liquorsekretion u. der Liquorzusammensetzung zu einigen Erkrankungen des inneren Ohres" Klin. Beitr. z. Ohrenhlkd., Urbantschitsch Festschrift p. 6751919 M. f. O. p. 9571920 (Abstract).

34) Yamaoka (H.), "A Method of Inoculating the Virus of Rabies" Kyoto, Ig. Z. Vol. 12 p. 4031915.

\section{Description of Colored Plates.}

PLATE I.

Fig. 1. Aquaeductus cochleae.

Immediately after the injection of an Indian ink suspension into the cisterna magna.

Fig. 2. Semicircular canal.

Thirty minutes after the injection of an Indian ink suspension into the cisterna magna.

Fig. 3. Crista ampullaris.

Four hours after the injection of an Indian ink sumpension into the cisterna magna.

Fig. 4. Vestibular end of the aquaeductus vestibuli.

Oz hour after the injection of an Indian ink suspension into the cisterna magna.

Fig. 5. A purt of the cochlea, including scala tympani, scala vestibuli, Reissner's membrane, limbus suirale, lamina spiralis, ganglion spirale, etc.

One month after the injection of Indian ink into the cisterna magna.

\section{PLATE II.}

Fig. 6. Ligamentum spirale, etc.

Immediately after the injection of a fer rocyanide solution into the cisterna magna.

Fig. 7. Corti's organ and its vicinity.

Immediately after the injection of a ferrocyanide solution into the cisterna magna.

Fig. 8. A part af the macula acustica.

Immediately after the injection of a ferrocyanide solution into the cisterna magna.

Fig. 9. A part of the saccus endolymphaticus.

Immediately after the injection of a ferrocyanide solution into the cisterna magna.

Fig. 10. A part of the vestibular nerve, situated in the bony capsule at the bottom of the auditory meatus.

Thirty minutes after the injection of a ferrocyanide solution into the cisterna magna.

\section{Explanation of Pictures.}

Fig. 1. Aquaeductus cochleae.

Immediately after the injection of Indian ink into the cisterna magna.

Fig. 2. Semicircular canal.

Thirty minutes after the injection of Indian ink into the cisterna magna.

Fig. 3. Crista ampullaris.

Four hours after the injection of Indian ink into the cisterna magna.

Fig. 4. Vestibular end of the aquaeductus vestibuli.

One hour after the injection of Indian ink into the cisterna magna.

Fig. 5. A part of the cochlea, including scala typani, scala vestibuli, Reissner's membrane, limbus spirale, lamina spiralis, ganglion spirale, etc.

One month after the injection of Indian ink into the cisterna magna. 
Fig. 6. Ligamentum spirale, etc. Immediately after the injection of a fertocyanide solution into the cisterna magna.

Fig. 7. Corti's organ and its vicinity.

Immediately after the injection of a ferrocyanide solution into the cisterna magna.

Fig. 8. A part of the macula acustica.

Immediately after the injection of a ferrocyanide solution into the cisterna magna.

Fig. 9. A part of the saccus endolymphaticus.

Immediately after the injection of a ferrocyanide solution into the cisterna magna.

Fig. 10. A part of the vestibular nerve, situated in the bony capsule at the bottom of the auditory meatus,

Thirty minutes after the injection of a ferrocyanide solution into the cisterna magna.

Fig. $11 \& 1 \%$ Shows the author's method of injection into the cisterna magna.

Notice: As microphotographs do not give a clear view of the granules either of Indian ink or of ferrocyanide, the above pictures, except Fig. $11 \& 12$, are taken from the colored drawings of the original sections. 